\title{
INVESTIGATION OF VIBRATIONS OF A LIGHTWEIGHT GRATE ON ELASTIC SUPPORTS OF A COARSE LITTER CLEANER WITH RANDOM DISTURBANCE FROM RAW COTTON
}

\author{
Orif Murodov ${ }^{1}$ \\ ${ }^{1}$ Tashkent Institute of Textile and Light \\ Industry, \\ Tashkent, \\ Uzbekistan
}

\author{
Shavkat Madrahimov ${ }^{2}$ \\ ${ }^{2}$ Tashkent Institute of Textile and Light \\ Industry, \\ Tashkent, \\ Uzbekistan
}

\author{
Ziyodullo Shodiyev ${ }^{3}$ \\ ${ }^{3}$ Bukhara Branch of The Tashkent Institute of \\ Irrigation and Agricultural \\ Mechanization Engineers, \\ Bukhara, \\ Uzbekistan
}

Article DOI: https://doi.org/10.36713/epra6042

\begin{abstract}
The article discusses the results of theoretical studies of vibrations of a plastic grate on elastic supports of a coarse litter cleaner under accidental exposure to raw cotton. Graphical dependences of changes in displacements and vibration rate of the grate on changes in the coefficients of stiffness, dissipation and on the disturbing load from raw cotton at various values of the grate mass are constructed. Based on the analysis of the obtained graphical dependencies, the values of the system parameters are recommended.
\end{abstract}

KEYWORDS: plastic grates, elastic supports, raw cotton, plastic pipes, mass, polyethylene, stiffness coefficient.

\section{INTRODUCTION}

Installation of an elastic sleeve on the grate support when dragging the raw cotton with a serrated cylinder allows the raw cotton to interact with the grates and impart an oscillatory motion to them, which contributes to additional shaking of the cotton volatiles and the release of trash [1].

Cotton fiber is the main raw material of the textile industry, and its products are in high demand in the world market. "International Cotton Advisory Committee (ICAC), in the 2016-2017 season, 24.55 million tons of fiber was consumed, while 23.07 million tons. In this regard, countries such as Bangladesh, China, Turkey and Indonesia have led in the import of cotton fiber. In this regard, special attention is paid to the development of new resource-saving techniques and technologies that will further increase the requirements for cotton fiber and its quality improve the quality and reduce the cost of cotton products. At the same time, the expansion of cotton fiber production in foreign countries remains an important task [1].

Research is being carried out around the world to develop innovative techniques and technologies for the ginning industry, which provide for the effective use of modern science and technology, and to improve existing ones. In this area, including in production, the development of working bodies, efficient, resource-efficient ginners of large cotton ginning machines is of great importance [2].

In our country, special attention is paid to the creation of technological processes of primary 
processing of cotton and high-efficiency technological machines and equipment for production, as well as their control systems. In particular, one of the most important issues is the creation of efficient cotton gin constructions and the introduction of effective technology for waste treatment in order to ensure the production of high quality cotton products from processed raw materials, depending on the initial performance of ginners [3].

An analysis of scientific studies has shown that the cleaning of cotton from large wastes was carried out to determine the diameters of the columns, the size of the holes formed by the interlocking, saw-cylinder, and the frequency of rotation of the saw-cylinder. Lightweight plastic vibrating moving structures of the columns are not considered on the basis of in-depth theoretical and practical research of their parameters [4].

\section{MATERIALS AND METHODS}

It should be noted that in the case of bar steel grates on elastic supports, the perturbing generalized force from the cotton being cleaned will be insufficient to ensure the grate vibrations with the required amplitude and frequency. Therefore, the grate is made of a plastic pipe and mounted on rubber elastic sleeves.

It is important to obtain the dependences of the change in the compressive force of the elastic support depending on the stiffness of the elastic element: a) at different masses of the grate; b) at different speeds of the serrated cylinder.

The difficult operating conditions of the grate, as well as the dependence of the nature of the vibrations on many factors, indicate the need to create a dynamic model of the vibrations of a plastic grate on elastic supports (in Fig. 1a) to calculate its rational parameters. A single mass oscillatory system (in Fig. 1b) with a random perturbing force was chosen as a dynamic model. The nature and value of the technological resistance were obtained by strain gauge during experiments with a laboratory setup [5].

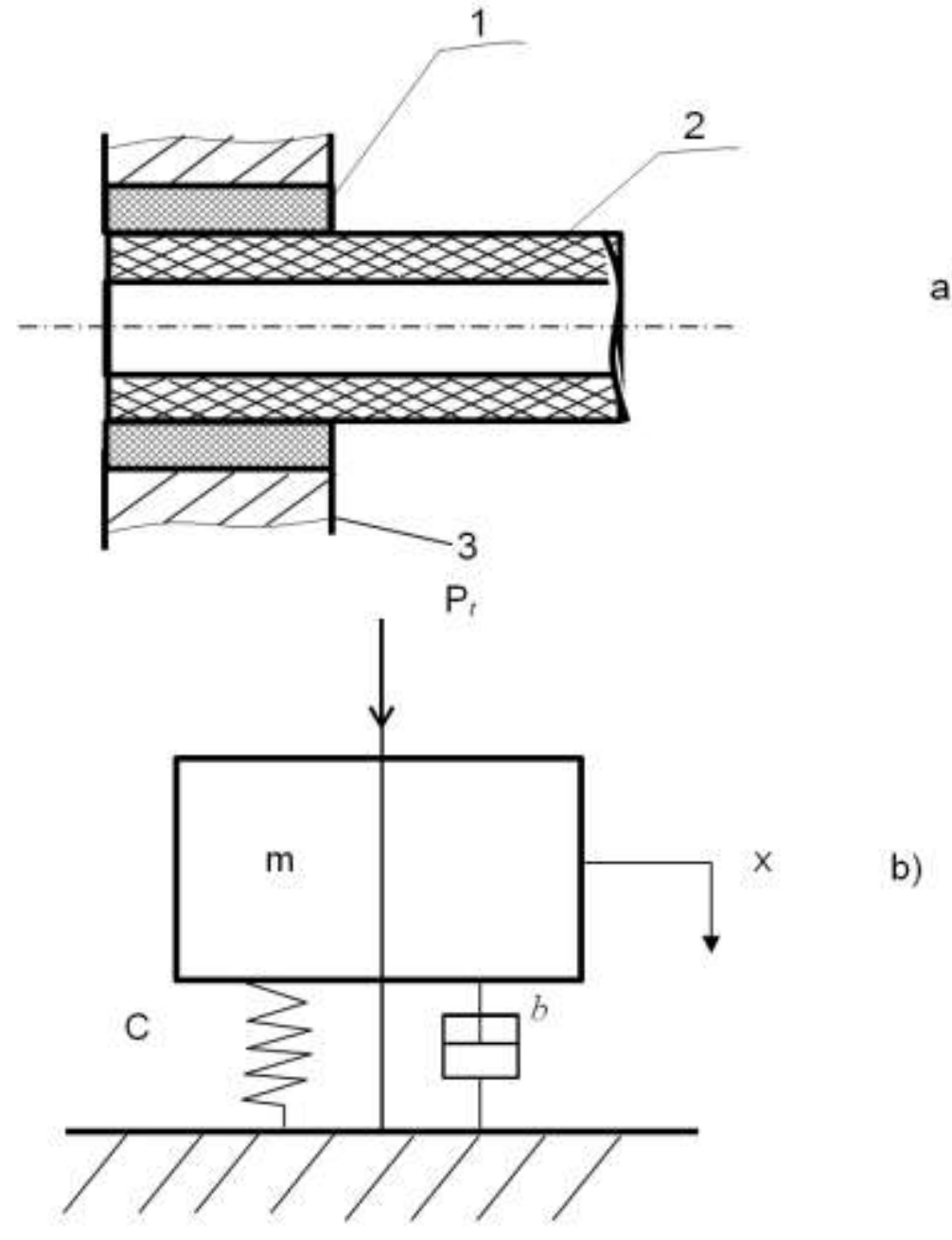

a)

Figure 1. Diagram of a plastic one on elastic supports (a) and a dynamic model of an oscillatory system (b): 1 - rubber support, 2 - grate, 3 - cleaner body 
The differential equation of vibrations of plastic polyethylene on rubber bushings of a raw cotton cleaner from coarse litter has the form [6]:

$$
m \ddot{x}+b \dot{x}+k x=P_{t}, \quad P_{t}=M\left(P_{t}\right) \pm \delta\left(P_{t}\right)
$$

The analytical solution of this nonlinear differential equation is practically difficult; therefore, its solution was made on a computer using standard programs. To determine the best parameters of plastic grates and plot graphical dependencies, variation studies were carried out with the following initial values:

$$
\begin{gathered}
m=1.85 \mathrm{Ns}^{2} / m, k=8600 \mathrm{~N} / \mathrm{m}, b=65 \mathrm{Ns} / \mathrm{m} \\
M\left(P_{t}\right)=22 \pm 3.02 \cos 30 x-1.97 \sin x+0.51 \cos 60 x+0.37 \sin 60 x
\end{gathered}
$$

Where, $\delta\left(P_{t}\right)$ - The random component of the technological load of cotton

The variation in the stiffness values of the elastic rubber sleeve is due to the fact that its value affects the dynamic process in the system, determines the occurrence of forced vibrations with a certain amplitude and frequency, which ensures the efficiency of the technological process of cleaning raw cotton from large trash impurities.

Based on the solution of problem (1), the dependences of the change in the displacement of the mass of the system $X$ are obtained in the technological mode of operation with varying the stiffness coefficient of the rubber sleeve. On the basis of the research results, a fairly rapid damping of the natural vibrations of one mass system (about $0.1 \mathrm{~s}$ ) and the correspondence of the forced vibrations of the grate mass to the nature of the approximated technological load from the cotton being pulled through were established. With an increase in the stiffness coefficient of the elastic support, a noticeable decrease in the amplitude of low-frequency vibrations occurs according to a nonlinear pattern.

\section{RESULTS AND DISCUSSION}

The results of the experiments showed that a plastic grate on an elastic base experiences from the raw cotton pulled by the saw cylinder $2.4-2.7$ times less than the relative load on the grate with a rigid support. The importance of taking into account the technological loads from cotton on the plastic grate is explained by the fact that their value varies widely depending on the supply of cotton (machine productivity) and has a random nature of the impact. Figure 2 Graphs of the dependence of the change in the displacement of the grate on elastic supports on the function of the grate mass and technological resistance from raw cotton are presented.

The determining component of the load fluctuation is a low frequency, which corresponds to the rotational speed of the saw cylinder of the cleaner. The high-frequency component is due to the uneven supply of raw cotton. At the design load in the system, the grates oscillate with small amplitude $(0.8 \div 1.0 \mathrm{~mm}$ ). With an increase in the load (up to 24 $\mathrm{N})$, the vibration amplitude of the grate increases to $(1.8 \div 3.0 \mathrm{~mm})$. With a further increase in the load, in practice, the slaughter of raw cotton usually occurs between the grate and the saw cylinder. Thus, with an increase in the stiffness coefficient of an elastic rubber support from 3.0 to $12.6 \mathrm{~N} / \mathrm{mm}$, the vibration amplitude of a plastic grate decreases in a nonlinear manner from $4.5 \cdot 10^{-3}$ to $2.91 \cdot 10^{-3} \mathrm{~m}$ with a grate mass $1.6 \mathrm{~kg}$, and with a grate weight of $2.0 \mathrm{~kg}$, it decreases from $3.52 \cdot 10^{-3}$ to $0.78 \cdot 10^{-3} \mathrm{~m}$ (see Fig.2a, curves 1, 2, 3)

Considering that significant changes in the grate vibration amplitude lead to exceeding the limits of the gap between the serrated cylinder and grate. The best values of the stiffness coefficient of the elastic support, providing the required gap size are $(0.8 \div$ $1.2) \cdot 10^{4} \mathrm{~N} / \mathrm{m}$.

The range of variation of the values of the dissipation coefficient, which characterizes the elastic support, was established according to the results of the experiment for rubber grade 1338. Allowance for dissipation is due to the ability to absorb free vibrations and a part of forced vibrations. The recommended values of the dissipation coefficient are $80-100 \mathrm{~N} \mathrm{~s} / \mathrm{m}$.

In fig. 2.b shows the graphical dependences of the change in the amplitude of the oscillations of the movement of the plastic grate with the change in the load from the cleaned raw cotton. 

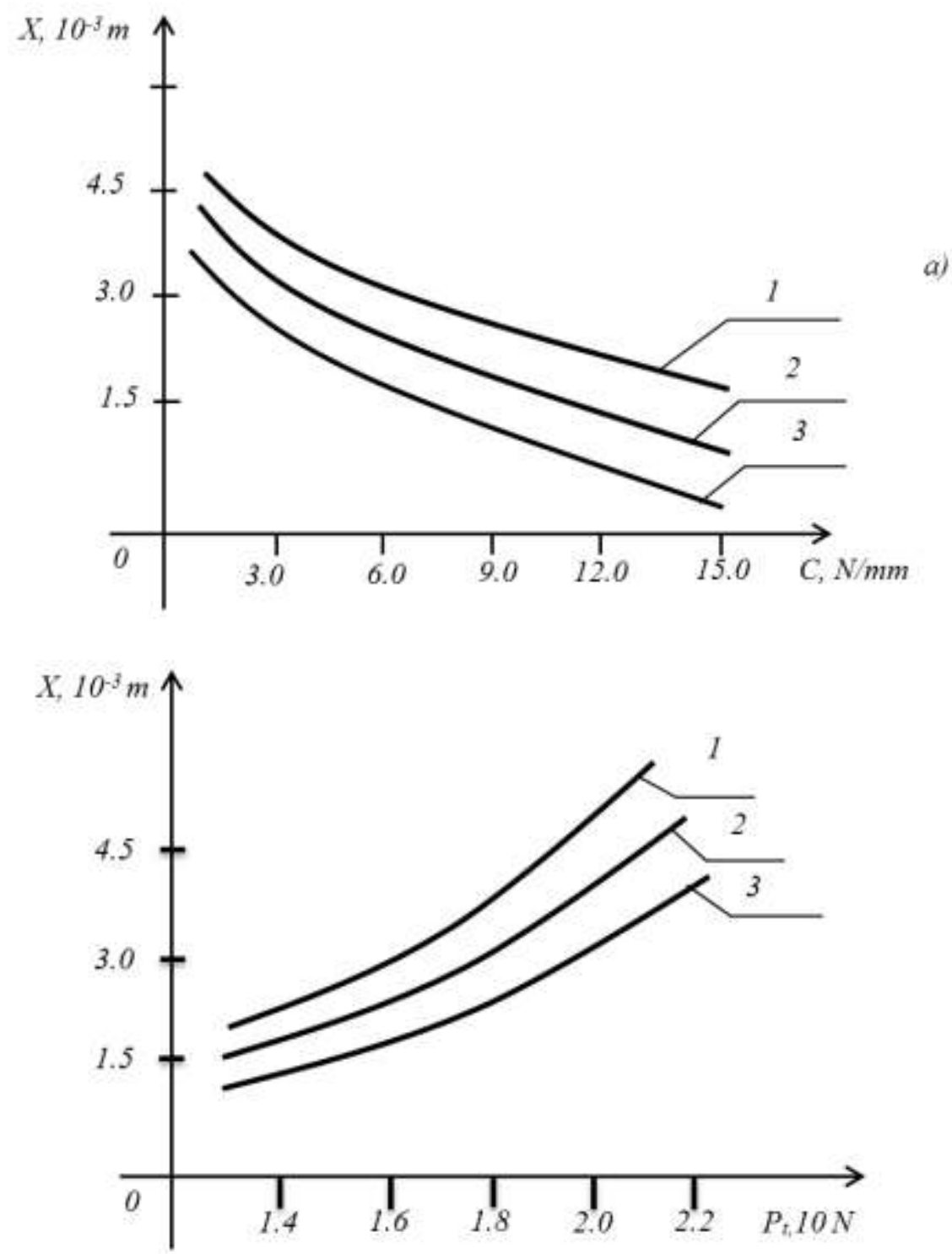

b)

Figure 2. Graphical dependences of the stiffness coefficient of an elastic rubber support at different mass: a - at different mass of a plastic grate from a cotton cleaner; $b$ - change in the amplitude of vibrations of the movement of the plastic grate: 1 -at $\mathrm{m}=1.6 \mathrm{~kg} ; 2-\mathrm{m}=1.8 \mathrm{~kg} ; 3-\mathrm{m}=$ $2.0 \mathrm{~kg}$, Deviation $\Delta \mathrm{X}=(\mathbf{5 . 0} \ldots \mathbf{7 . 0})$

With an increase in the load of the grate from raw cotton during its cleaning from $15.5 \mathrm{~N}$ to $24.0 \mathrm{~N}$, the vibration amplitude of the grate increases from $1.58 \cdot 10^{3}$ to $4.54 \cdot 10^{3} \mathrm{~m}$ for normal preservation of the gap between the surface of the saw cylinder and the grate, $X=\left(\begin{array}{lll}2.0 & \ldots 2.3\end{array}\right) \cdot 103 \mathrm{~m}$ the load should not exceed $(18.0 \ldots 22.5) \mathrm{N}$. 


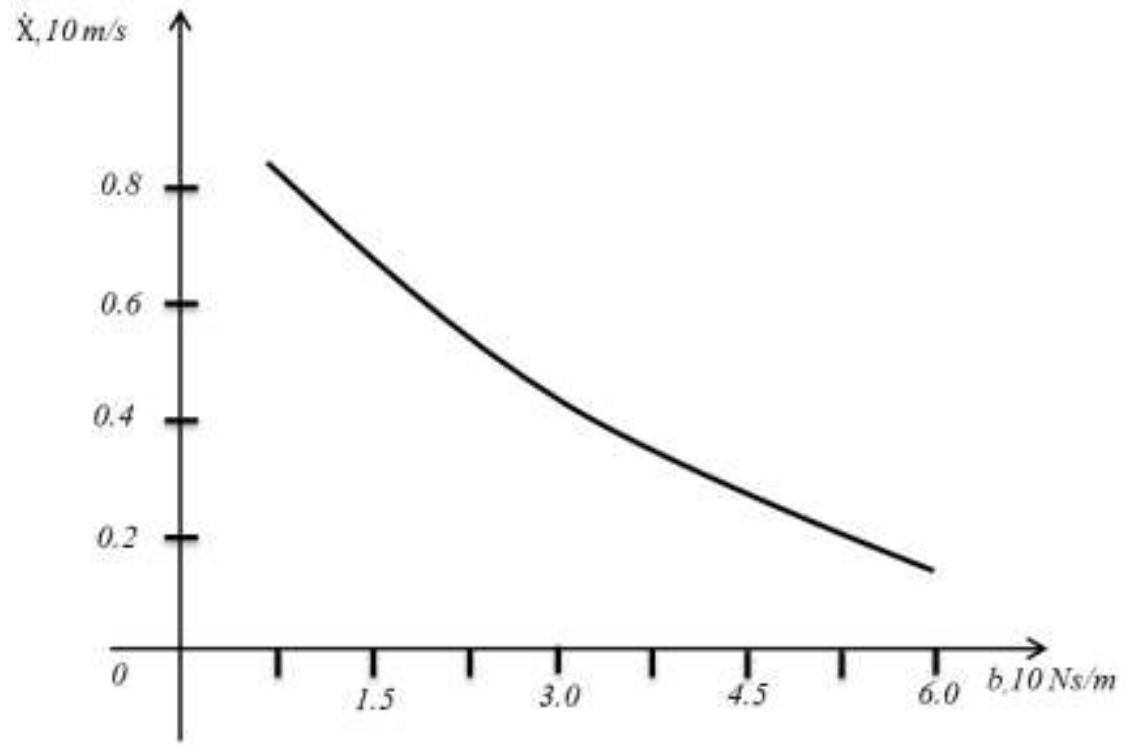

Figure: 3. Graphical dependence of the change in the vibration speed of the plastic grate on the increase in the dissipation coefficient of the elastic support

It is known $[7,8]$ that the coefficient of dissipation affects the amplitude of vibrations and allows the necessary damping of natural vibrations of a plastic grate. In this case, it is important to select the values of the dissipation coefficient of the elastic rubber support of the grate of the cotton cleaner from coarse litter.

\section{CONCLUSIONS}

In fig. 3 shows the graphical dependences of the change in the grate vibration speed on the variation of the dissipation coefficient of the rubber sleeve. It can be seen from the figure that the oscillation rate decreases with an increase in the dissipation coefficient according to a nonlinear pattern. The recommended values of the dissipation coefficient are $(48 \ldots 55) \mathrm{Ns} / \mathrm{m}$.

\section{REFERENCES}

1. D.S Tashpulatov, A.Juraev, O.J Murodov, J.K Gafurov, S.Vassiliadis Aegean International Textile and Advanced Engineering Conference (AITAE 2018) IOP Conf. Series: Materials Science and Engineering459 (2019) 012068.

2. Murodov $O 2019$ Perfection of designs and rationale of parameters of plastic Koloski cleaning cleaners International Journal of Innovative Technology and Exploring Engineering 8(12) 2640-46

3. Khojiev M. T., Juraev A. D., Murodov O. Dj. and Rakhimov A. K. Development of design and substantiation of the parameters of the separator for fibrous materials. International Journal of Recent Technology and Engineering, 2019, 8(2) 5806-11

4. Rajabov O. and Shodiyev Z. Analysis of Small Fluctuations of a Multifaceted Mesh under the Influence of Technological Load from the Cleaned Cotton - Raw. International Journal of
Advanced Research in Science, Engineering and Technology, 2019, 6(10) 11396-99

5. Anvar J. and Ozod R. Analysis of the Interaction of Fibrous Material with a Multifaceted Grid of the Cleaner. International Journal of Recent Technology and Engineering, 2019, 8(1) 2661-66

6. M.T. Khodjiev, O.J. Murodov, D.Eshmurodov. Creation of Scientific-Based Construction of the Separator with Insulation Camera. International Journal of Innovative Technology and Exploring Engineering, 2020, 9(4)

7. O. I. Rajabov, A. S. Abrorov, N. I. Mirzaqulova, G. B. Zaripov, Kh. S. Ziyodullaev, "An experimental study of the location of the grid bars cells installed under spiked cylinders in a cotton cleaner from small waste", IOP Conference Series: Materials Science and Engineering, (2020), 734(1) 012073.

8. Rajabov $O$, Fazliddin $K$, and Salimov Sh., "Substantiation of Parameters of the Fibrous Material Cleaning Zone", International Journal of Engineering and Advanced Technology, vol. 9, No 3, (2020), pp. 1052-1057. 